\title{
PRECISION FEED BUDGETING IN PRACTICE
}

\author{
O. F. PARKER
}

Ruakura Animal Research Station, Hamilton

\section{A bstract}

The case for feed budgeting on intensively stocked farms is briefly discussed, and a summary is given of the information required to draw up a meaningful feed budget. Therefore, after describing the procedure followed at Ruakura, particular attention is given to the problems and pitfalls in accurately assessing pasture cover, both before and after grazing. Photographs are used to illustrate many of the situations encountered in the day-to-day use of the pasture assessment technique.

\section{INTRODUCTION}

SiNCE Ruakura's inception as an Animal Research Station, the nutrition of cattle and sheep has been one of its main preoccupations. The work has indicated the effects on animal production of varying feeding levels at different physiological stages through the year so that seasonal feed supplies and changing animal requirements may best be integrated to achieve high performance from animals at high stocking rates. Considerable understanding has been gained of the nutritional requirements of pasture-fed animals and how these are best catered for.

With cows whose total feed supply is derived from pasture and pasture products, very great differences in production can be caused by fairly small differences in the absolute amounts and distribution of feed consumed, especially before calving (Hutton and Parker, 1973). Because of this, a simple but fairly precise means of registering, reviewing and, if necessary, revising the overall feed situation on farms becomes a matter of prime concern. Until this is available and put to regular use, New Zealand farmers - and especially dairy men — will remain unable quantitatively to ration feed to stock in accordance with their needs, and much of the farms' and animals' inherent potential for high production must stay unrealized. 


\section{RUAKURA PRACTICE}

The present 1973-4 season is the ninth consecutive year in which the assessment and recording of pasture dry matter (DM) by eye has been a regular weekly feature of farming operations at Kuakura. In many short-term experiments., it is even being used daily to monitor and maintain pre-set levels of pasture intake or utilization by cattle.

The routine followed during the current long-term experiment with dairy cows provides a detailed general picture of the methods used.

Five groups of cows, each on farms of 25 paddocks, are stocked at rates of between 4.1 and $5.6 \mathrm{cows} / \mathrm{ha}$. The 125 paddocks involved are patrolled every Monday by two experienced pasture dry matter assessors who walk the entire length of every paddock, moving from one side to the other as they do so. Because paddock cover is usually variable, each man ascribes a mark or grade to each fifth of the paddock as he crosses it, mentally adds the grades and hence 'arrives at an average grade for each paddock. The mean of each man's final grade is then recorded against the paddock concerned and multiplied by 300, the sum then representing the pasture cover as $\mathrm{kg} \mathrm{DM} / \mathrm{ha}$.

Single-digit grades are used since the number of sums involved makes grading of actual DM involving three- and fourfigure numbers unrealistic, unfair, and prone to error.

Obviously regular check measures of pasture DM changes are needed. This is done by choosing 5 paddocks out of the 25 in each treatment as representative of the whole for pasture and soil type. Every time each one of these 25 "indicator" paddocks is grazed, five plot cuts are taken from it immediately before and after grazing. Each plot is enclosed by a reinforced wooden frame or quadrat which is placed over a portion of the pasture representative of each fifth of the paddock as 'assessed immediately beforehand. To minimize between-operator error, and to account for all the pasture DM present, each plot is cut to absolute ground level with a shearing hand-piece fitted to a portable minishear (Fig. 1). On average, about two "indicator" paddocks are grazed every day during the main pasture growth period from September to April. There are (therefore a number of checks of the assessments every day during that time.

Because each plot is cut to ground level, the pasture is washed to remove soil before being dried in a forced draught oven so it is not a cutting and drying technique that can readily be 


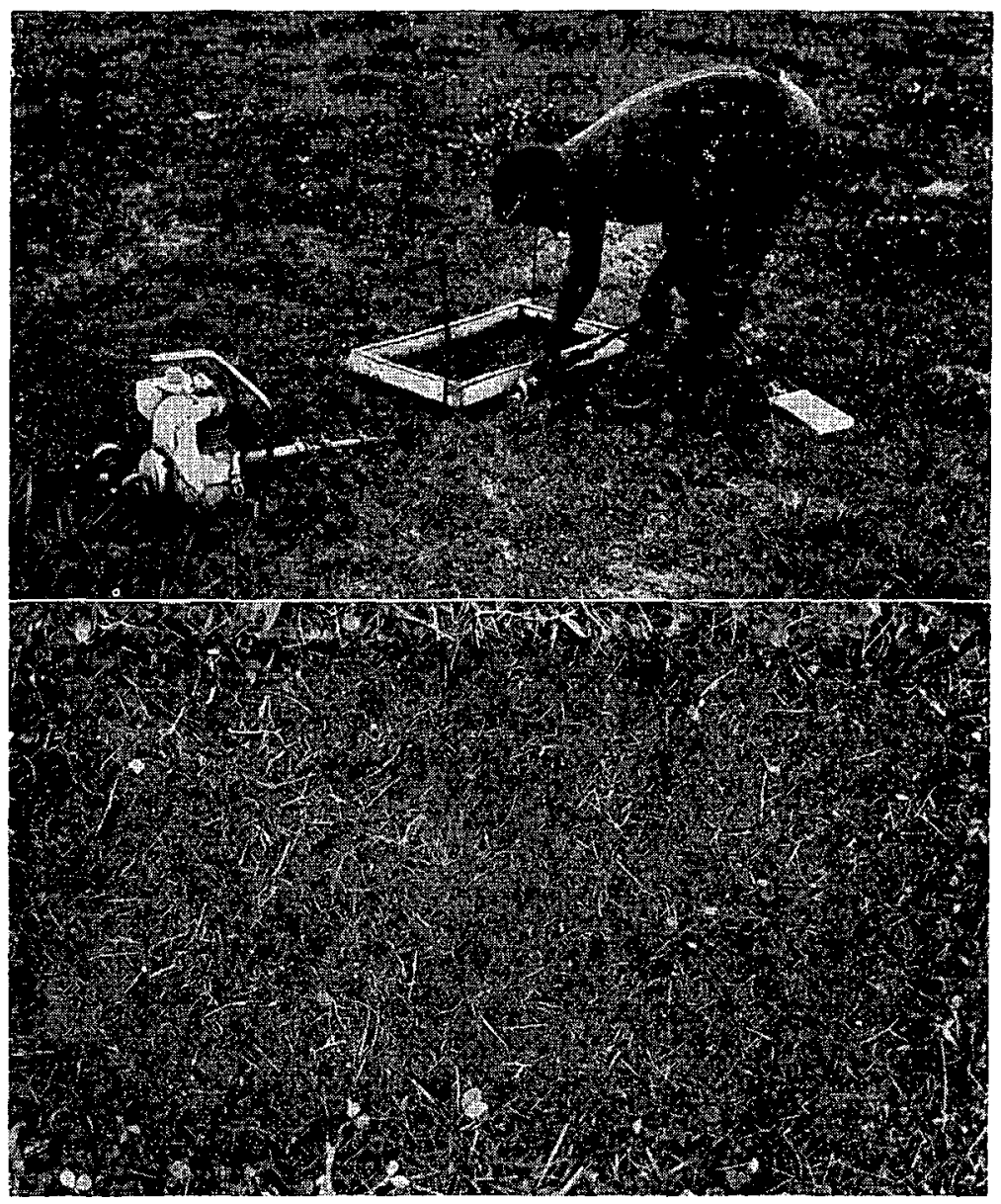

Fig. 1: Top — Plot cutting gear. Bottom — Plot cut to ground level.

used by farmers! However, by enabling the operators to keep close to the mark it directly serves the advisers and farmers who accompany them on their grading rounds each week.

From the weekly grading of the whole farm, paddocks are ranked from heaviest to lightest, and this determines the subsequent stack grazing rotations and general feed reviews. The indicator paddocks provide information on pasture growth rates. 'From this information it has been established that the average pasture growth rate at Ruakura is about $17000 \mathrm{~kg} \mathrm{DM} / \mathrm{ha} / \mathrm{yr}$, 
that about $90 \%$ of this can be utilized by cows, that up to 4.9 cows/ha can be carried on a self-contained basis, and that about $650 \mathrm{~kg}$ of milk-fat/ha can be produced each year by rather average quality identical twin cows.

\section{FACTORS INFLUENCING ASSESSMENT OF TOTAL DRY MATTER}

In visually assessing total dry matter (TDM), account must be taken of both the amount of pasture herbage present, which is influenced by the height and density of the swerd - in their turn affected by botanical composition - and of the DM content of the herbage, which varies with stage and speed of growth, species present, weather and season.

\section{PASTURE HEIGHT AND DENSITY}

Long pastures may have more total DM per unit of area than short ones, but per unit of height shorter pastures contain more DM because they have a higher proportion of ungrazed basal plant tissue, stems and dead material having a higher DM content than leaves.

For this reason it is essential that density be most carefully appraised. It depends very much on the intensity and frequency of grazing, for heavily stocked, frequently grazed pastures are more dense than! those growing under more lax grazing.

\section{BOtANICAL COMPOSITION}

Height, density and DM content of pastures are all affected by botanical composition.

Over much of the northern half of the North Island (including most of the major dairying "areas), so-called "ryegrass-clover" pastures often contain a high proportion - even a seasonal dominance - of $\mathrm{Pm}$ species and paspalum. Under intensive grazing Poa can be near dominant in late winter and early spring. In comparison with ryegrass at that time they have a much denser growth form, mature more rapidly, but at a lower height, with the result that, other "things being equal, pastures containing them are likely to have a higher DM content than those without.

By contrast, paspalum dominance should not greatly influence TDM provided such swards are grazed hard and often. Under such a regime paspalum makes a similar contribution to ryegrass at the same stages of growth. However, being a sub-tropical 
species, paspalum in summer Passes through its vegetative stages very rapidly, so that if grazed leniently it oan assume a pervading dominance yielding much TDM, but relatively little ADM for milking cows (Fig. 2) .

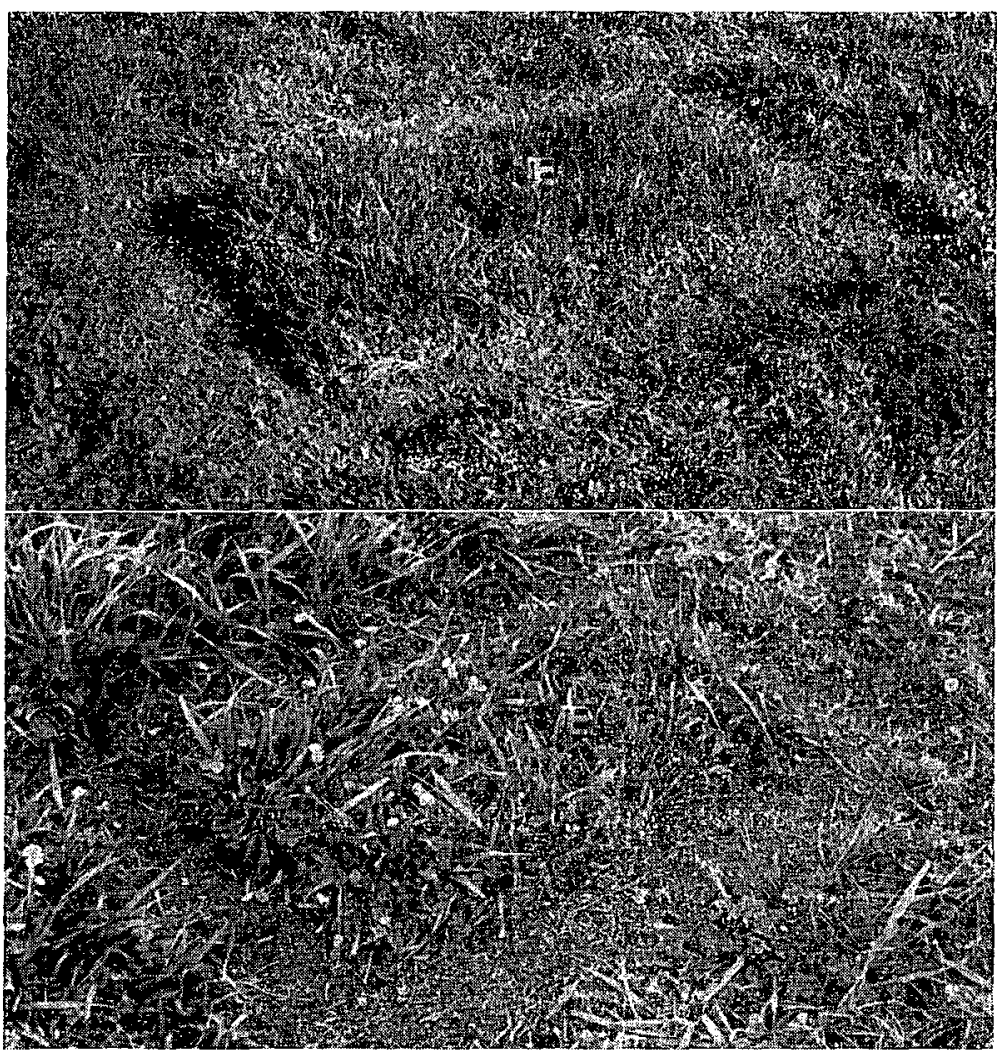

FIG. 2: Top - Poa-dominant pasture in winter $(2350 \mathrm{~kg} \mathrm{DM} / \mathrm{ha})$.

Bottom $\rightarrow$ Paspalum-dominant pasture in summer $(2800 \mathrm{~kg} \mathrm{DM} / \mathrm{ha})$.

Because white clover has both a lower dry matter content and a less dense growth form than most grasses, clover dominance at any time of the year lowers TDM for a given pasture height.

Pastures grazed laxly can accumulate a massive undergrowth of Yorkshire fog and browntop, and the dry matter content of such swards can rise to extremely high levels, particularly when undergrazed through late autumn and winter. 


\section{Dry Matter Percentage}

TDM is greatly influenced by the DM percentage of the sward. This tends to be lowest in rapidly growing pastures. At Ruakura it generally ranges from about $11 \%$ in winter-spring to about $30 \%$ in late summer, with day-to-day variation at any time likely to be \pm 3 or 4 percentage units, owing mainly to variable weather factors. Such small daily changes cannot be visualized with any preoision, nor for practical purposes does it matter.

\section{FACTORS INFLUENCING THE PERCENTAGE AVAILABILITY}

\section{OF DM}

The ADM of a sward is a different amount for different types of stock at different times of the year and is thus one of the most potent factors affecting both pasture and animal performance.

It 'has. been found in the Ruakura environment that production from unsupplemented grazing milking cows is reduced if they have to use $40 \%$ or more of the TDM present at each grazing (J. B. Hutton, unpublished) . It is also restricted if they are forced to graze below certain levels of DM remaining after grazing. These base levels of residual DM range from about 1350 $\mathrm{kg} / \mathrm{ha}$ in spring up to about $2000 \mathrm{~kg} / \mathrm{ha}$ in a dry summer (Fig. $3)$. On the other hand, dry cows or supplemented milkers in late lactation will happily graze to a residual DM as low as 500 $\mathrm{kg} / \mathrm{ha}$, which could represent a utilization of $85 \%$ or more of the pasture present before grazing.

To the extent that they affect the proportion of pasture used at each grazing, speed of rotation and soil moisture status can have a marked effect on the availability of feed. These are additional but important issues to take into account when drawing up feed budgets.

\section{DISCUSSION}

Until farm advisers, and through them farmers, become more proficient at assessing the quantities of pasture DM present on paddocks, there must be a communication gap (if not one of credibility) between stock needs as defined by research workers and the extent to which that knowledge can properly be used in the field. Without pasture assessment how can farmers or their advisers quantitatively ration feed to stock? Suoh a technique should be recognized as an integral part of improved feed budget- 


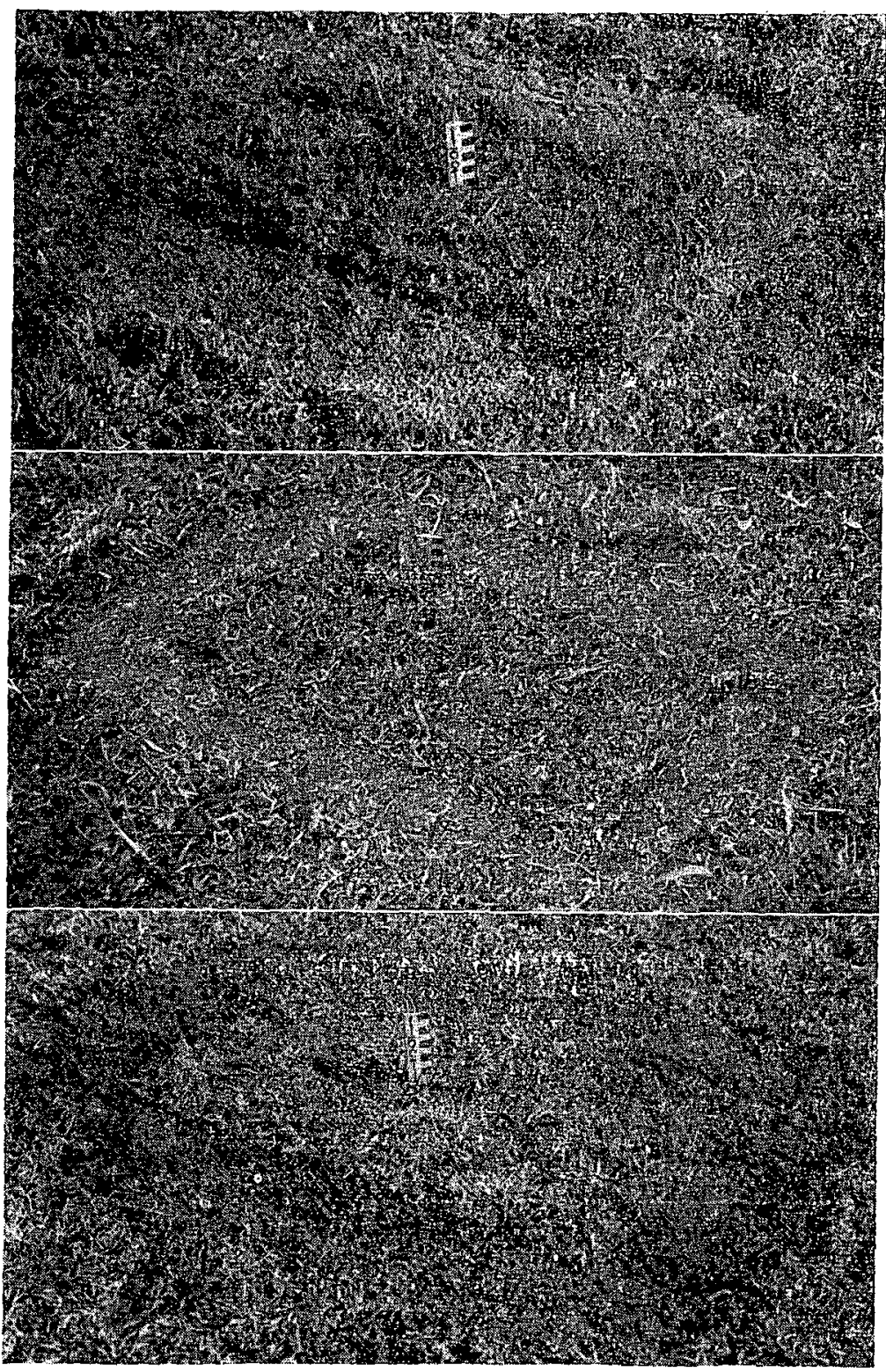

FIG. 3: Top $1350 \mathrm{~kg} \mathrm{DM} / \mathrm{ha}$ (spring). Middle $-1700 \mathrm{~kg} \mathrm{DM} / \mathrm{ha}$ (summer). Bottom - $500 \mathrm{~kg} D M /$ ha (winter). 
ing, for without competent pasture assessment a feed budget can be neither accurate nor a real check on the efficacy of the feeding standards being used. With the addition of any supplementary feed on hand, use of the technique makes farmers aware of the 'amount of feed they have on their farms at any one time. But to make best use of such information it is essential that they also know rates of change in growth rates, quality and amounts of pasture, effective areas of their farms, precise areas of their paddocks and, not least, appreciate how their cows' needs and ability to utilize pasture will change through the year. Happily, scientists, advisory officers and farmers are now taking an increasing interest in the technique. However, the importance of frequent re-checking of visual appraisals with measurements of total dry matter made to ground level cannot be over-stressed.

\section{CONCLUSION}

Eye assessment of pasture dry matter by a competent operator permits a degree of precision in planning stock grazing rotations, feed budgets and animal intakes that cannot be equalled by any other system that remains practical on a farm scale.

\section{ACKNOWLEDGGMENTS}

To Dr J. B. Hutton, M. W. Harbord and L. Powell for helpful criticism and advice.

\section{REFERENCES}

Hutton, J. B.; Parker, 0. F., 1973: N.Z. Jl agric. Res., 16: 95-104. 